\title{
Assessment of Dothistroma Needle Blight of Pinus radiata Using Airborne Hyperspectral Imagery
}

\author{
N. Coops, M. Stanford, K. Old, M. Dudzinski, D. Culvenor, and C. Stone
}

First, second, and fifth authors: CSIRO Forestry and Forest Products, Private Bag 10, Clayton South 3169, Vic Australia; third and fourth authors: CSIRO Forestry and Forest Products, P.O. Box E4008, Kingston ACT 2604 Australia; and sixth author: Research and Development Division, State Forests of NSW, P.O. Box 100, Beecroft, NSW 2119 Australia.

Accepted for publication 7 July 2003.

\begin{abstract}
Coops, N., Stanford, M., Old, K., Dudzinski, M., Culvenor, D., and Stone, C. 2003. Assessment of Dothistroma needle blight of Pinus radiata using airborne hyperspectral imagery. Phytopathology 93:15241532.

Dothistroma needle blight is a serious foliar disease in Australian Pinus radiata plantations causing defoliation, decreased productivity and, in extreme cases, tree death. Conventional methods of monitoring forest health such as aerial survey and ground assessments are labor intensive, time consuming, and subjective. Remote sensing provides a synoptic view of the canopy and can indicate areas affected by damaging agents such as pests and pathogens. Hyperspectral airborne remote sensing imagery (CASI-2) was acquired over pine stands in southern New South
\end{abstract}

ABSTRACT

Dothistroma needle blight is a serious foliar disease which occurs in over 30 conifer species and has been observed in many countries, including Australia, Chile, New Zealand, South Africa, and the United States $(14,26)$. The cause is a fungal pathogen, Dothistroma septospora (Doroguine) Morelet (syn. D. pini Hulbary), teleomorph Mycosphaerella pini Rostr. in Munk, which attacks and kills pine needles of all ages $(14,30,44,51)$. Within Australia, Dothistroma needle blight affects Pinus radiata D. Don plantations and occurs periodically in eastern Australia and Tasmania (45). Infection occurs sporadically and early symptoms consist of yellow and tan spots on needles, which turn brown to reddish brown and often girdle needles as reddish bands. The needles become necrotic and are shed. The disease is most prevalent in wet conditions because spores are dispersed by rain splash (therefore, the disease may be more severe on lower branches) and infection can occur in successive years, resulting in decreased growth and, sometimes, death of individual crowns of young trees (21).

In Australia, aerial photography, visual aerial surveillance, and field-based detection surveys are among the primary techniques used to detect and delineate pest infestations within forests and plantations (39). However, Dothistroma needle blight often is visible only from aircraft in the advanced stages of the epidemic and, as a result, there has been a longstanding need for an early-assessment capacity to map the extent and severity of the disease.

Advances in remote sensing technology, such as hyperspectral (i.e., many narrowly defined spectral channels) imagery coupled with the greater availability and lower cost of high spatial resolution satellite imagery $(<5 \mathrm{~m})$, provide new opportunities for

Corresponding author: N. Coops; E-mail address: Nicholas.coops@csiro.au

Publication no. P-2003-0930-01R

(c) 2003 The American Phytopathological Society
Wales, Australia which had been ground assessed and ranked on an individual tree basis, according to the extent of Dothistroma needle blight. A series of spectral indices were tested using two different approaches for extracting crown-scale reflectance measurements and relating these to ground-based estimates of severity. Dothistroma needle blight is most severe in the lower crown and statistically significant relationships were found between crown reflectance values and ground estimates using a 'halo' approach (which ignored each tree crown's brightest central pixels). Independent accuracy assessment of the method indicated that the technique could successfully detect three levels of Dothistroma needle blight infection with an accuracy of over $70 \%$.

Additional keyword: spectral reflectance.

early assessment and delineation of a range of forest health conditions. Once developed and tested, these techniques offer the potential to be applied operationally and should improve the ability to map those stands at high risk of infection or infestation. In addition, the digital nature of this type of information allows these data to be integrated easily into forest management systems.

The spectral characteristics of vegetation are governed primarily by the scattering and absorption features of the internal structure of the leaf and the leaves' biochemical constituents, such as pigments, water, nitrogen, cellulose, and lignin $(2,9)$. Recent research has established relationships between leaf reflectance spectra and foliar biochemicals, especially the photosynthetic pigments $(2,11,12)$, which then can provide information on the physiological status of vegetation which, in turn, is affected by a variety of stress factors $(7,43)$. In addition, a variety of biochemical components such as proteins (nitrogen), cellulose, starch, lignin, and water all have been estimated from dry and fresh leaf spectra for a range of species $(2,11,13,16,22,55,59)$. Leaf reflectance also provides an indication of the integrative effect of genetic, developmental, and environmental factors on vegetation through their influence on physical and biochemical properties $(17,19,25)$. For example, leaf reflectance has been associated with insect infestation through damage or removal of the waxy cuticle (48), destruction of cell walls, and intercellular integrity and subsequent net reduction in leaf moisture (37).

In particular, these studies have focussed on the sensitivity of the visible and near-infrared region (NIR) of the electromagnetic spectrum to detect changes in the condition of vegetation $(28,33,47,58)$; in particular, reduction in chlorophyll $(1,4,6$, 38). This region is important because it exhibits the greatest change in reflectance per unit change in wavelength of any green leaf spectral feature in visible and NIR wavebands (15). Selected wavelengths within this region, known as the "red-edge" (defined as the region between 690 and $740 \mathrm{~nm}$ ) (10), can provide 
early indications of plant stress $(4,5,28,53)$ or onset of disease $(43,60)$.

This article reports research which developed relationships between spectral indices derived from the visible and NIR region of the electromagnetic spectrum, obtained from a hyperspectral sensor, and the severity of Dothistroma needle blight in $P$. radiata.

\section{MATERIALS AND METHODS}

Study site. The study site is situated within Buccleuch State Forest $\left(148.0^{\circ} \mathrm{E}, 30.0^{\circ} \mathrm{S}\right)$ in New South Wales (NSW), Australia. The region covers the alpine and tableland environments of the Australian high country and the slopes and plains of southwestern NSW. This area has been a focus of significant $P$. radiata plantation activity since the 1950s. In 2000-01, the region experienced increased rainfall in the spring and early summer months, creating the most favorable wet soil conditions in a decade for epidemics of Dothistroma needle blight.

Assessment of Dothistroma needle blight damage. Two sites were chosen within existing commercial $P$. radiata plantations covering a broad range of Dothistroma needle blight impacts. Site 1 (northern site) was planted in 1994 and site 2 (southern site) was planted in 1995 at standard 1,100 stem/ha stocking, resulting in a simple understory of grass. Crown diameter generally ranged from 3 to $7 \mathrm{~m}$. Elevation (mean altitude above sea level) ranged from 720 to $860 \mathrm{~m}$. Soils in the area are clay loam to light clay texture, formed from Young Granodiorite dominated by well-drained Red Kandosols (29). At each site, line transects were established and approximately 300 trees were ground assessed for the severity of Dothistroma needle blight on a scale of 1 to 6 using the classification system shown in Table 1 . Given the similar age classes at the two sites, tree height was relatively similar compared with the overall variation in the plantation estate. Each tree crown was manually identified on the Compact Airborne Spectrographic Imager (CASI-2) data and 100 trees were randomly selected for model development.

Hyperspectral data acquisition and processing. The CASI-2 is a charge-coupled, push-broom imaging spectrograph capable of providing imagery over a 545-nm spectral range between 400 and $1,000 \mathrm{~nm}$ with a $37.8^{\circ}$ field of view across track. Pixel resolutions can vary from submeter to $10 \mathrm{~m}$ depending on aircraft altitude. The spectral bands on the CASI-2 are programmable prior to flight. In this study, 10 spectral bands were preselected based on previous work (8) (Table 2). To minimize bidirectional reflectance and to cover the study area, flight lines were oriented parallel to the solar azimuth. Imagery was acquired on 4 April 2001 as a series of north-south strips under cloud-free conditions at $0.8-\mathrm{m}$ spatial resolution.

The flight lines covered pseudo-invariant features (PIFs) with known spectral properties to assist in image calibration. CASI-2 imagery was converted from digital numbers to physical units of radiance (microwats per centimeter squared per steradian per nanometer. Down-welling irradiance was sampled coincident with image acquisition from the roof of the aircraft using an Incident Light Sensor system (ITRES Research, Calgary, Alberta, Canada). Radiance then was converted to reflectance using an empirical line correction method (ELC) in the ENVI image-processing system (46). The ELC uses two or more spectra as obtained from field-based spectrometers and compares them to the single pixel spectra of PIFs on the image. The calibration technique forces image data to match selected field reflectance spectra using a linear regression for each band to equate digital count and reflectance. This is equivalent to removing the solar irradiance and the atmospheric path radiance (31).

Foliar crown selection. When utilizing high spatial resolution imagery, such as reflectance measured using CASI-2 at a spatial resolution of $0.8 \mathrm{~m}$, the method used to sample the spectral signature for each individual crown is critical. When viewing high spatial resolution imagery of tree crowns, significant brightness variation exists, depending on the pixel position within the crown. This may be caused by a number of factors, including the canopy architecture and local viewing and illumination conditions (35) at the time of data capture. Leckie (34) compared a number of sampling methods to extract spectral signatures of individual tree crowns from high spatial resolution remotely sensed imagery. The four methods compared were average pixel reflectance intensities for (i) the whole crown, (ii) the sunlit portion of the crown, (iii) the shaded portion, and (iv) the single brightest pixel at the top of the tree (34). It was concluded that either the whole tree or the sunlit tree sampling method was the most suitable method for crown attribute modeling (34) based on crown spectra.

In this study, initially, each selected crown was manually delineated on the CASI-2 imagery on the computer screen and the whole tree spectral response extracted. A second method (termed 'halo') also was applied based on our understanding that the central pixel in the tree crown often is brighter than the surrounding ones, with these outer surrounding pixels (halo pixels) appearing to provide the most appropriate indication of the canopy condition. As a result, these halo pixels may provide a better indication of crown condition than the simple mean spectral response of the whole crown. In addition, the benefit of not including the central pixel in the crown delineation is that needle blight develops in the lower crown and the upper whorls of the trees were uniformly healthy at the time of image acquisition. The proposed relationship between the progression of crown symptoms and the response pattern within a window of pixels is shown in Figure 1. As the level of Dothistroma needle blight increases and green needle area is lost, the photosynthetic activity of the crown progressively declines. Based on this model, the halo-sampling strategy excludes the local maxima of pixel intensity correspond-

TABLE 2. Compact Airborne Spectrographic Imager-2 selected wavelengths used for data acquisition

\begin{tabular}{lcc}
\hline Band & Band center $(\mathrm{nm})$ & Band width $(\mathrm{nm})$ \\
\hline 1 & 450 & 9.6 \\
2 & 550 & 9.8 \\
3 & 635 & 9.8 \\
4 & 680 & 9.8 \\
5 & 700 & 9.8 \\
6 & 720 & 9.8 \\
7 & 740 & 9.8 \\
8 & 760 & 9.8 \\
9 & 780 & 9.8 \\
10 & 850 & 10 \\
\hline
\end{tabular}

TABLE 1. Description of ground-assessed Dothistroma needle blight severity classes ${ }^{\mathrm{a}}$

\begin{tabular}{|c|c|}
\hline Class & Description \\
\hline 1 & Trees with little or no symptoms of disease. \\
\hline 2 & Minor defoliation to less than $1 \mathrm{~m}$ in height, few symptoms evident above this level. Affected whorls with up to $20 \%$ needle blight. \\
\hline 3 & Moderate defoliation to $\approx 2 \mathrm{~m}$. Affected whorls with 21 to $40 \%$ needle blight. \\
\hline 4 & Moderately defoliation to 2 to $3 \mathrm{~m}$. Affected whorls with 41 to $60 \%$ needle blight. \\
\hline 5 & Severe defoliation to 2 to $4 \mathrm{~m}$. Affected whorls with 61 to $80 \%$ needle blight. \\
\hline 6 & Very severe defoliation to $\approx 4$ to $6 \mathrm{~m}$. Affected whorls with 81 to $100 \%$ needle blight. \\
\hline
\end{tabular}

a The scoring protocol is aimed to grade the range of crown conditions observed across the stand as evenly as possible. 
ing to the apical portion of the tree (resulting in approximately 5 to 10 pixels per crown). These individual pixel values of the halo response are averaged to provide a mean reflectance value for the crown.

Spectral indices evaluated. An example of the mean spectral response of a healthy needle in the visible and NIR region of the electromagnetic spectrum, over a range similar to that detected by the CASI-2 sensor, is shown in Figure 2. Key distinguishing features include increased reflectance in the green wavelengths, an increase in red light absorbance (decrease in reflectance), and the steep increase in reflectance from the edge of the red to the peak in NIR reflectance at $\approx 700$ to $750 \mathrm{~nm}$. A detailed review of a range of spectral indices which have been applied to vegetation spectra is provided by Thenkabail et al. (54). Generally, three primary types of indices have been computed from spectral data sets. These are simple ratios, normalized difference ratios, and measure the red edge. The CASI-2 imagery was acquired only in $10 \mathrm{spec}-$ tral channels; therefore, not all previously published indices can be computed readily because many of the key selected wavelengths were not available. As a result, we computed a range of indices, given our wavelength selection, including single spectral wavelengths and representatives of the three index types.

Single wavelengths and simple ratio indices. A simple ratio index typically divides the reflectance at one reference wavelength by an index wavelength. Carter (3) measured narrow wavebands from a field-based spectroradiometer to evaluate the effectiveness of indices to predict plant stress. Several ratios, C(1) $=680 / 760 \mathrm{~nm}$ and $\mathrm{C}(2)=720 / 760 \mathrm{~nm}$, were highly significant in detecting stressed and nonstressed foliage for a variety of stress agents. Gamon and Surfus (20) proposed using a combination of an index of red and green wavelengths which specifically target anthocyanins. The index is a ratio of the sum of the red wavelengths (600 to $700 \mathrm{~nm}$ ) over the sum of the green wavelengths (500 to $600 \mathrm{~nm}$ ). In addition, the spectral reflectance in each of the 10 CASI-2 channels was tested separately.

Normalized difference indices. These indices subtract rather than divide the reflectance at the index wavelength from the reference wavelength. The Normalized Difference Vegetation Index (NDVI) (48) which has been shown, both empirically and theoretically, to be related to the fraction of photosynthetically active radiation absorbed in vegetation canopies $(32,49,50)$ were compared to the Dothistroma needle blight classes. The NDVI originally was designed for broadband sensors (such as Landsat MSS). However, these wide wavelength centers can be substituted with simple narrow wavelengths bands. In this research, we utilized the normalized ratio of narrow band reflectance at $680 \mathrm{~nm}$ (red) and $860 \mathrm{~nm}$ (NIR) wavelengths following the work of Merton and Harvey (41).

Red-edge indices. Linear regressions based on the slope of the red edge (red edge versus wavelength) can be used to describe the mathematical relationship between reflectance and wavelength (40). Red-edge spectra generally are asymptotic to near linear; therefore, it is appropriate to model spectral trends using linear regression. For the purpose of identifying simple measures of red edge, we computed the lower slope of the red edge, calculated as the slope of the line between the wavelength intervals 680 and $720 \mathrm{~nm}$, and the upper slope, calculated between wavelength intervals 720 and $740 \mathrm{~nm}$. The Red-edge Vegetation Stress Index (RVSI) was developed by Merton and Harvey (41) to identify vegetation stress based on spectral changes in upper red-edge geometry. The RVSI indicates the spectral concavity of the red edge based on the displacement in reflectance between a "modeled" linear midpoint (defined as mean reflectance of two bisecting points, the red-edge break-point [714 nm] and the start of the NIR plateau $[752 \mathrm{~nm}])$, and the "data" midpoint value. The difference

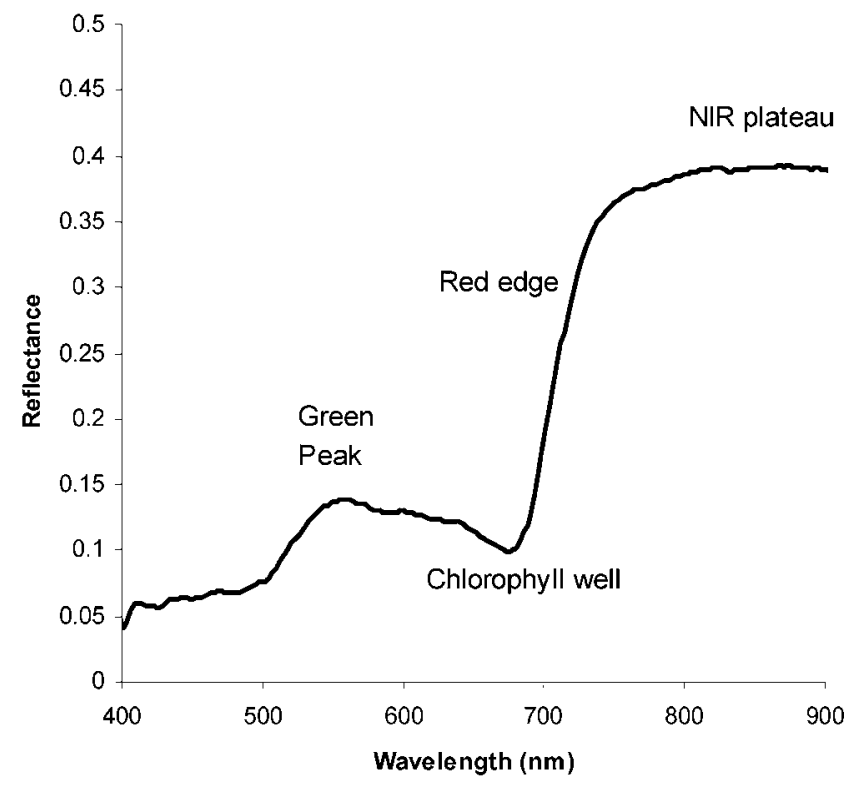

Fig. 2. Form and major features of healthy needle spectra in the visible and near-infrared regions of the electromagnetic spectrum.

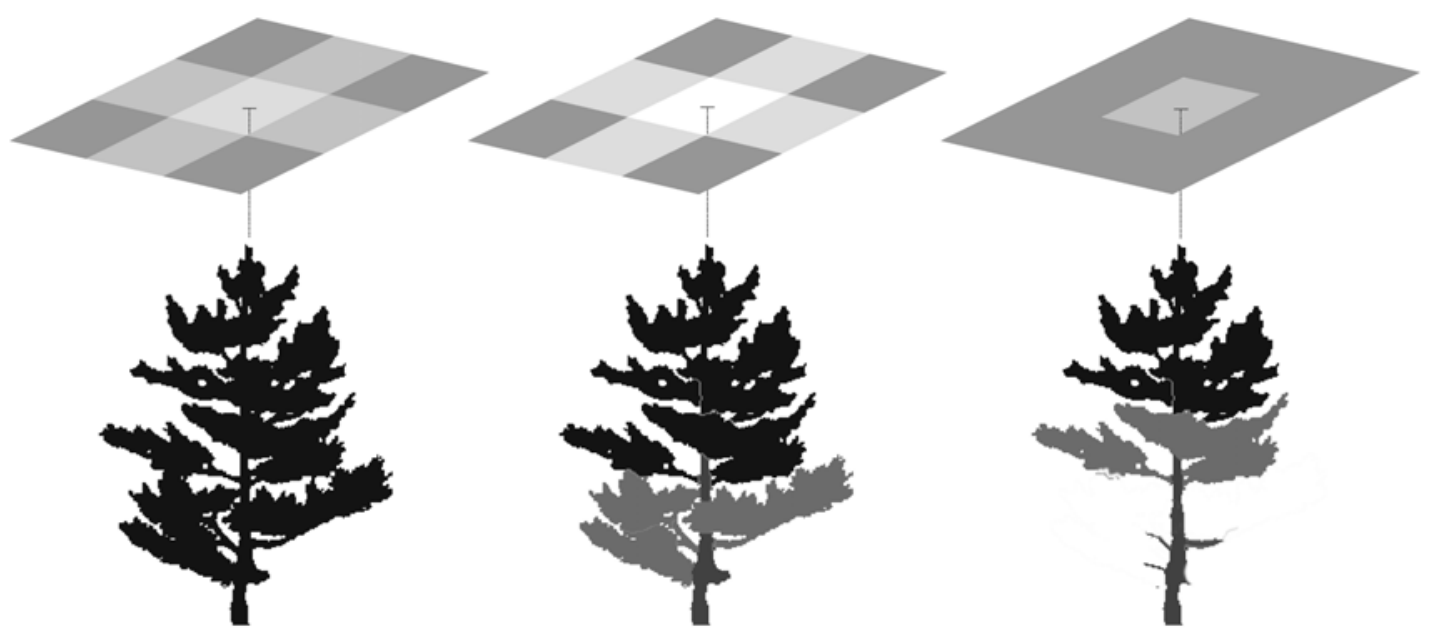

Fig. 1. Proposed relationship between the progression of crown symptoms and the near-infrared region reflectance pattern within a window of pixels. As the level of Dothistroma needle blight increases, the photosynthetic activity of the crown progressively declines. A 'halo' sampling strategy excludes the local maxima of pixel intensity corresponding to the apical portion of the tree. The remaining pixel values then are averaged to provide a mean reflectance value for the crown. 
between the two values then can be expressed as positive (stressed) or negative (nonstressed) values.

$$
\left(\frac{\rho_{714}+\rho_{752}}{2}\right)-\rho_{733}
$$

where $\rho_{714}=$ reflectance at $714 \mathrm{~nm}, \rho_{752}=$ reflectance at $752 \mathrm{~nm}$, and $\rho_{733}=$ reflectance at $733 \mathrm{~nm}$.

The CASI-2 equivalent of the index becomes

$$
\left(\frac{\rho_{720}+\rho_{760}}{2}\right)-\rho_{740}
$$

where $\rho_{720}=$ reflectance at $720 \mathrm{~nm}, \rho_{760}=$ reflectance at $760 \mathrm{~nm}$, and $\rho_{740}=$ reflectance at $740 \mathrm{~nm}$.

In order to undertake an initial first pass on the indices, correlation analysis was used to assess if significant relationships existed between the mean crown spectra and Dothistroma needle blight severity classes. If a significant relationship did not exist between the crown class and each index, it was not included in further analysis. Once key indices were selected, two analysis of variance (ANOVA) comparisons were undertaken $(27,61)$ to compare needle blight classes for each of the indices in order to ascertain which of the indices consistently discriminated at least some of the Dothistroma needle blight classes. ANOVA analysis was used to understand the variance relationships between the two data sets.

The first ANOVA compared the capacity of the indices to discriminate between each of the Dothistroma needle blight classes and the second was undertaken to assess the between-class variation between the northern and southern sites. Once the most appropriate index was selected, a simple linear regression (SLR) model that transforms the index values to needle blight classes was fitted, which provided an indicator of the statistical goodness of fit and the standard error for the prediction.

Once the pixel-by-pixel classification was completed using the developed relationship between reflectance index and needle blight class, a clustering approach was developed to produce a coherent image of tree crowns rather than a simple pixel-by-pixel interpretation of the image. Conceptually, the procedure simply compares the peaks of the tree crowns to the surrounding canopy on the
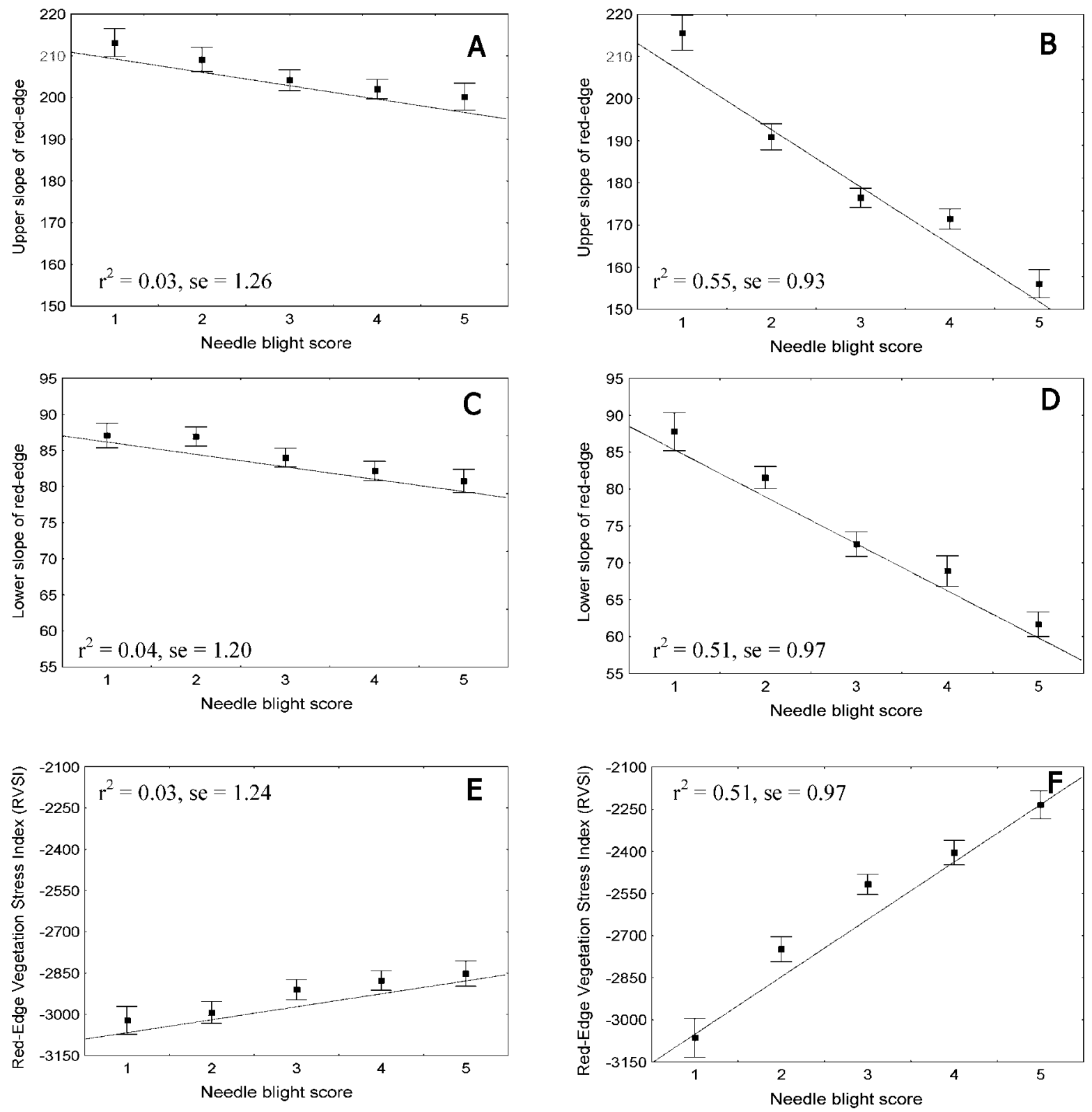

Fig. 3. Mean crown and standard error responses of the A, upper and $\mathbf{C}$, lower red-edge slope and the E, Red-edge Vegetation Stress Index (RVSI) for the individually delineated mean tree crowns over the two sites and mean crown and standard error responses of the $\mathbf{B}$, upper and $\mathbf{D}$, lower red-edge slope and the F, RVSI for the individually delineated halo tree crowns over the two sites. Also shown is the $r^{2}$ and the standard error of the relationship between each index and the Dothistroma needle blight severity score. 
assumption that the central peak (or brightest central pixel of the crown) is not a good indicator of the overall canopy status. The procedure compares the estimated Dothistroma needle blight score of the central pixel with its surrounding pixels. If the central Dothistroma needle blight score is lower (healthier) than its surrounding pixels, then its score is reduced until it matches its surrounding neighbors. If the pixel value in the center is the same as its neighboring pixels, then the crown is assumed to be homogeneous and the mean crown response is indicative of the overall canopy health.

To provide an independent assessment of the accuracy of the technique, an equation was developed using only crowns from the northern site and applied to the southern site as an independent validation of the model and technique. This partitioned data set allowed the development of a confusion matrix which provides measures of both omission errors (producer's accuracy) and commission errors (user's accuracy) (36) as an overall indication of the accuracy of the crown class predictions in the southern site. Producer's accuracy was calculated by dividing the total number of "matched" score tree crowns by the total number of trees measured in the field. User's accuracy is calculated by dividing the total number of matched score trees by the total number of field-measured trees identified on the imagery. The matrix indicates the number of times that crowns, scored in the field, matched exactly the needle blight class predicted by the imagery.

In order to complete the matrix, each crown located in the field was located on the imagery. The reflectance data from each lo- cation then were transferred to the predicted needle blight classification, which utilized both the spectral transformation and the spatial clustering technique. The centroid of each tree then was compared with the corresponding cluster on the prediction. As a result, the accuracy matrix will contain two error situations. First, a misclassification of the needle blight class simply due to the accuracy of the transformation model or the clustering approach and, second, errors associated with image misregistration. The second type of error occurred if the individual tree measured in the field could not be located accurately on the imagery, or if its crown was unable to be clearly identified.

\section{RESULTS}

Examination of the field data indicated that, although the scoring system encompassed six classes of needle blight, no class 6 cases were found within the trees selected for model development. Therefore, only five classes of Dothistroma needle blight were included in this analysis. An initial pass of the correlations between the computed indices and the Dothistroma needle blight scores indicated that three reflectance indices had significant correlations at the $P<0.05$ level. These three indices were the lower and upper slope of the red edge and the RVSI. Mean and standard error responses of the upper and lower red-edge slope of the electromagnetic spectrum and the RVSI for the individually delineated mean tree crowns and crowns as delineated using the

TABLE 3. Analysis of variance (ANOVA)results for northern and southern sites with spectra extracted using two crown methods: Mean (full crown digitized) and Halo (sampling excludes the local maxima of pixel intensity corresponding to the apical portion of the tree) ${ }^{\mathrm{a}}$

\begin{tabular}{|c|c|c|c|c|c|c|c|c|c|c|}
\hline \multirow[b]{2}{*}{ Score ${ }^{b}$} & \multicolumn{5}{|c|}{ Northern site } & \multicolumn{5}{|c|}{ Southern site } \\
\hline & 1 & 2 & 3 & 4 & 5 & 1 & 2 & 3 & 4 & 5 \\
\hline \multicolumn{11}{|c|}{ Upper slope } \\
\hline \multicolumn{11}{|l|}{ Halo } \\
\hline 1 & $\ldots$ & $* * *$ & $* * *$ & $* * *$ & $* * *$ & $\ldots$ & $\ldots$ & $\ldots$ & $* * *$ & $* * *$ \\
\hline 2 & $\ldots$ & $\ldots$ & $* * *$ & $* *$ & $* * *$ & $\ldots$ & $\ldots$ & $\ldots$ & $* *$ & $* * *$ \\
\hline 3 & $\ldots$ & $\ldots$ & $\ldots$ & $\ldots$ & $*$ & $\ldots$ & $\ldots$ & $\ldots$ & $* * *$ & $* * *$ \\
\hline 4 & $\ldots$ & $\ldots$ & $\ldots$ & $\ldots$ & $* *$ & $\ldots$ & $\ldots$ & $\ldots$ & $\ldots$ & $*$ \\
\hline 5 & $\ldots$ & $\ldots$ & $\ldots$ & $\ldots$ & $\ldots$ & $\ldots$ & $\ldots$ & $\ldots$ & $\ldots$ & $\ldots$ \\
\hline \multicolumn{11}{|l|}{ Mean } \\
\hline 1 & $\ldots$ & $\ldots$ & $\ldots$ & $\ldots$ & $\ldots$ & $\ldots$ & $\ldots$ & $\ldots$ & $\ldots$ & $\ldots$ \\
\hline 2 & $*$ & $\ldots$ & $\ldots$ & $\ldots$ & $\ldots$ & $\ldots$ & $\ldots$ & $\ldots$ & $\ldots$ & $\ldots$ \\
\hline 3 & $* *$ & $\ldots$ & $\ldots$ & $\ldots$ & $\cdots$ & $\ldots$ & $\ldots$ & $\cdots$ & $\ldots$ & $\ldots$ \\
\hline 4 & $*$ & $\ldots$ & $\ldots$ & $\ldots$ & $\ldots$ & $*$ & $* * *$ & $\ldots$ & $\ldots$ & $\ldots$ \\
\hline 5 & $* *$ & $\ldots$ & $\ldots$ & $\ldots$ & $\ldots$ & $*$ & $* *$ & $*$ & $\ldots$ & $\ldots$ \\
\hline \multicolumn{11}{|c|}{ Lower slope } \\
\hline \multicolumn{11}{|l|}{ Halo } \\
\hline 1 & $\ldots$ & $* * *$ & **** & $* * *$ & $* * *$ & $\ldots$ & $\ldots$ & $\ldots$ & $*$ & $* * *$ \\
\hline 2 & $\ldots$ & $\ldots$ & $* * *$ & $* *$ & $* * *$ & $\ldots$ & $\ldots$ & $\ldots$ & $* * *$ & $* * *$ \\
\hline 3 & $\ldots$ & $\ldots$ & $\ldots$ & $\ldots$ & $\ldots$ & $\ldots$ & $\ldots$ & $\ldots$ & $*$ & $* * *$ \\
\hline 4 & $\ldots$ & $\ldots$ & $\ldots$ & $\ldots$ & $\ldots$ & $\ldots$ & $\ldots$ & $\ldots$ & $\ldots$ & $\ldots$ \\
\hline 5 & $\ldots$ & $\ldots$ & $\ldots$ & $\ldots$ & $\ldots$ & $\ldots$ & $\ldots$ & $\ldots$ & $\ldots$ & $\ldots$ \\
\hline \multicolumn{11}{|l|}{ Mean } \\
\hline 1 & $\cdots$ & $\cdots$ & $\cdots$ & $\cdots$ & $\cdots$ & $\cdots$ & $\cdots$ & $\cdots$ & $\cdots$ & $\cdots$ \\
\hline 2 & $\ldots$ & $\cdots$ & $\ldots$ & $\cdots$ & $\cdots$ & $\ldots$ & $\ldots$ & $\cdots$ & $\cdots$ & $\cdots$ \\
\hline 3 & $* *$ & $\ldots$ & $\ldots$ & $\ldots$ & $\ldots$ & $\ldots$ & $\ldots$ & $\ldots$ & $\ldots$ & $\ldots$ \\
\hline 4 & $*$ & $\ldots$ & $\ldots$ & $\ldots$ & $\ldots$ & $*$ & $* *$ & $*$ & $\ldots$ & $\ldots$ \\
\hline 5 & $* *$ & $*$ & $\ldots$ & $\ldots$ & $\ldots$ & $\ldots$ & $\ldots$ & $\ldots$ & $\ldots$ & $\ldots$ \\
\hline \multicolumn{11}{|l|}{ RVSI } \\
\hline \multicolumn{11}{|l|}{ Halo } \\
\hline 1 & $\ldots$ & $* * *$ & $* * *$ & $* * *$ & $* * *$ & $\ldots$ & $\ldots$ & $\ldots$ & $* * *$ & $* * *$ \\
\hline 2 & $\ldots$ & $\ldots$ & $* * *$ & $* * *$ & $* * *$ & $\ldots$ & $\ldots$ & $\ldots$ & $* * *$ & $* * *$ \\
\hline 3 & $\ldots$ & $\ldots$ & $\ldots$ & $\ldots$ & $*$ & $\ldots$ & $\ldots$ & $\ldots$ & $* *$ & $* * *$ \\
\hline 4 & $\ldots$ & $\ldots$ & $\ldots$ & $\ldots$ & $*$ & $\ldots$ & $\ldots$ & $\ldots$ & $\ldots$ & $\ldots$ \\
\hline 5 & $\ldots$ & $\ldots$ & $\ldots$ & $\ldots$ & $\ldots$ & $\ldots$ & $\ldots$ & $\ldots$ & $\ldots$ & $\ldots$ \\
\hline \multicolumn{11}{|l|}{ Mean } \\
\hline 1 & $\ldots$ & $\ldots$ & $\ldots$ & $\ldots$ & $\ldots$ & $\ldots$ & $\ldots$ & $\ldots$ & $\ldots$ & $\ldots$ \\
\hline 2 & $*$ & $\ldots$ & $\ldots$ & $\ldots$ & $\ldots$ & $\ldots$ & $\ldots$ & $\ldots$ & $\ldots$ & $\ldots$ \\
\hline 3 & $* * *$ & $\ldots$ & $\ldots$ & $\ldots$ & $\ldots$ & $\ldots$ & $\ldots$ & $\ldots$ & $\ldots$ & $\ldots$ \\
\hline 4 & $* *$ & $\ldots$ & $\ldots$ & $\ldots$ & $\ldots$ & $*$ & $* *$ & $*$ & $\ldots$ & $\ldots$ \\
\hline 5 & $* * *$ & $\ldots$ & $\ldots$ & $\ldots$ & $\ldots$ & $\ldots$ & $\ldots$ & $\ldots$ & $\ldots$ & $\ldots$ \\
\hline
\end{tabular}

${ }^{a}$ Level of significance using ANOVA: *, **, and $* * *=P<0.05,0.01$, and 0.001 , respectively.

${ }^{\mathrm{b}}$ Halo $=$ halo method of crown extraction, Mean $=$ mean crown extraction, RVSI $=$ Red-edge Vegetation Stress Index. 
halo method are shown in Figure 3. Responses for the upper slope of the red-edge mean crown and halo-derived data are shown in Figure $3 \mathrm{~A}$ and $\mathrm{B}$, respectively. Results for lower slope of the red edge are shown in Figure 3C and D, and RVSI results are shown in Figure $3 \mathrm{E}$ and $\mathrm{F}$. A simple linear regression line was fitted to the data (shown) with the $r^{2}$ value and the standard error of the estimate (Dothistroma needle cast units; also shown).

We assessed statistical differences between Dothistroma needle blight scores for each index using a one-way ANOVA with a Tukey's HSD post hoc analysis. Results of the ANOVA for the

TABLE 4. Statistical comparisons of Mean (full crown digitized) and Halo (sampling excludes the local maxima of pixel intensity corresponding to the apical portion of the tree) crown extraction methods for selected indices

\begin{tabular}{lccccc}
\hline & \multicolumn{5}{c}{ Dothistroma crown condition class ${ }^{\mathrm{a}}$} \\
\cline { 2 - 5 } Index, method & 1 & 2 & 3 & 4 & 5 \\
\hline Upper & $* * *$ & $\ldots$ & $* * *$ & $\ldots$ & $\ldots$ \\
Halo & $* *$ & $\ldots$ & $\ldots$ & $* * *$ & $*$ \\
Mean & & & & & \\
Lower & $* * *$ & $\ldots$ & $\ldots$ & $\ldots$ & $\ldots$ \\
Halo & $* * *$ & $\ldots$ & $\ldots$ & $* * *$ & $\ldots$ \\
Mean & & & $\ldots *$ & & \\
RVSI & $* * *$ & $\ldots$ & $* *$ & $\ldots$ & $\ldots$ \\
Halo & $* * *$ & $\ldots$ & $\ldots$ & $* * *$ & $\ldots$ \\
Mean & &
\end{tabular}

a $*, * *$, and $* * *=P<0.05,0.01$, and 0.001 , respectively.

${ }^{\mathrm{b}}$ Red-edge Vegetation Stress Index. northern and southern sites, for the upper and lower red edge, and the RVSI using both the halo- and mean-sampling methods are shown in Table 3. The matrices show the level of significance (*, $* *$, and $* * *=P<0.05,0.01$, and 0.001 , respectively) between Dothistroma needle blight classes using the halo and the mean crown sampling and each of the three indices. The results indicate that upper red-edge reflectance of the mean sampled crowns is poor at discriminating the classes, with only class 1 being statistically different from the other classes. Using the halo-sampling method, all classes can be discriminated at the $P<0.05$ level except for class 3 from class 4 . The most significant degree of separation occurs between classes 1 and all other classes, classes 2 and 3, and classes 2 and 5. The data for the southern site indicate that there is less separation between the classes, with neither method distinguishing class 1,2 , or 3 . Classes 4 and 5 can be statistically distinguished from the other classes using both methods, with the halo-sampling method producing more statistically distinct separation.

The results for lower slope and RVSI show that the degree of separation between classes was improved significantly using the halo-sampling approach, rather than sampling using the mean of the whole individual crown. In terms of discriminating power, the upper slope index appears to be the most powerful, with more degrees of significance than either the RVSI, which appears to be the second in discriminating power, or the lower slope, which is the poorest. Discrimination between classes appears to be more successful on the northern site, where disease was more severe, compared with the southern site (Table 3).
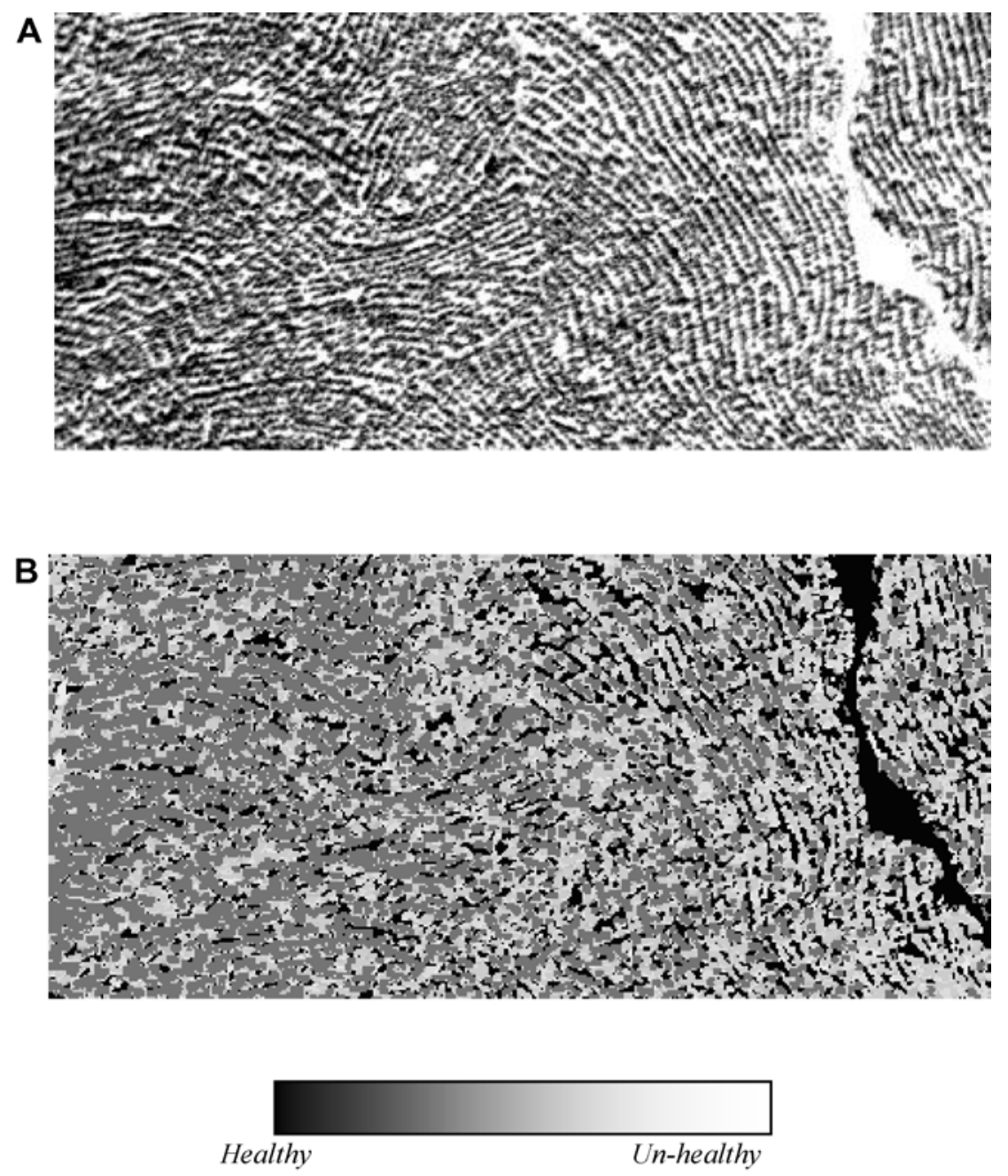

Fig. 4. A, Upper slope of red edge Compact Airborne Spectrographic Imager-2 image over a Pinus radiata plantation and B, map of needle blight severity classes across the plantation using red-edge prediction and spatial clustering. 
An indication of the potential robustness of the indices over both sites is shown in Table 4. If the index is to be applied in an operational scheme, it is important that the index discriminate not only Dothistroma needle blight classes but also that the index is robust (i.e., that the spectra of class 1 at one site is similar to the spectra of a class 1 crown at another site). Therefore, in Table 4, the index is robust if the ANOVA is not significant. All the indices have considerable variation between the northern and southern site in their spectral characterization of class 1 (Table 4). The mean sampling method produces significantly different spectral descriptions of Dothistroma needle blight class 4 regardless of the index applied. Class 3 is different between the northern and southern site only when sampled by the halo method using the upper slope index. Generally, there is discrimination between a number of the scores using both the mean- and halo-sampling methods; however, halo sampling produces a much greater range in the index than the mean crown extraction method. Again, the halo-derived index is unable to reliably distinguish spectral responses of classes 3 and 4 , but discriminates between other classes effectively.

An example of the upper slope of the red-edge image and the output of the needle blight prediction developed for forest affected by Dothistroma needle blight using the clustering algorithm is shown in Figure 4.

The accuracy of the technique using the independent southern site data set for validation is shown in Table 5. The success with which the reflectance characteristics of crowns can be used to assign needle blight classes depends on the severity of disease (Table 5). The most accurately predicted class is 4 , which has a producer's accuracy of $40 \%$ (calculated as 6 crowns which were predicted and observed as class 4 out of a total of 15 class 4 crowns). The unhealthy class 5 has the lowest accuracy, with only $11 \%$ accuracy using the independent data set. The average accuracy across all classes using the five-score system is $28 \%$. As indicated by the ANOVA results, in some cases there is only limited spectral discrimination between a number of the classes, especially between needle blight classes 2,3 , and 4 . As a result, the classification scheme may be more appropriately simplified to a threeclass (for example, low, medium, or high) variable. A modified accuracy matrix assessed the accuracy of the technique, assuming that a misclassification of one class on either side of the correct value still constituted a correct classification (Table 5). This matrix shows that the accuracy of the technique has increased, with all classes being assigned with at least $70 \%$ accuracy.

\section{DISCUSSION}

Assessment of forest health formerly has relied on manual ground and aerial surveys by trained forestry personnel. These techniques often are subjective and labor intensive; however, they can provide a holistic assessment and evaluation of a variety of forest health and growth conditions, or combination of conditions, and, to date, there is still a lack of more efficient and accurate technologies. The application of high spectral and spatial resolution remote sensing data for the assessment of plantation health and condition, while not eliminating the need for ground-based inspection by tree health experts, allows the current health surveillance programs to be properly targeted and cost effective. These remote sensing systems provide information on canopy condition via the physiological functioning of the stand as well as the use of structure (such as crown shape). The capacity of the imagery to provide a spatial context which can be merged readily with other sources of spatial information, such as digital terrain models and global positioning system information, will enable a more precise mapping base for plantation management.

The use of the six-class Dothistroma needle blight classification system applied in this study has allowed the initial steps of a canopy health score index based on remotely sensed data to be developed. Importantly, the selected upper slope of the red-edge index appears to be able to provide some discriminating power between Dothistroma needle blight classes but, also, good predictors for the northern and southern sites. These are key properties of any remote sensing index because they provide confidence, not only in the capacity of the index to predict differences at one site, but also to be consistent in its prediction at a second site. As expected, the accuracy of the index was improved considerably if the health assessment classes were reduced to a three-class classification, in which case the accuracy of the model reached over $90 \%$ for some classes. The aggregation of the six-class classification system into three or four classes could be undertaken based on management decisions, with class boundaries defining a specific management decision or action. For example, aggregation of levels 4 to 6 may lead to a decision to spray or salvage while levels 2 and 3 may lead to a decision to refly the area at a later date, and so on. Future work should validate this proposed aggregation.

In the future, it is anticipated that high spatial and high spectral resolution (1 to $4 \mathrm{~m}, 256$ bands at 10-nm spectral widths) will be available from space-based platforms, although a combination of these two capabilities may still be some way off. Operation of a space-based health surveillance system obviously will help in reducing the costs associated with flying hyperspectral scanners in aircraft. A key capacity of an airborne-based monitoring system, however, is the capacity to acquire imagery at opportunistic times. This is an important benefit for forest health monitoring because infestation and infection often are linked to other events, such as disturbance, increased rainfall, phenology of the forest type, and infecting agent (52). As a result, regardless of the platform, the seasonal date of image acquisition is an important factor in

TABLE 5. Predicted accuracy of the Dothistroma needle cast using a five-level and three-level classification system ${ }^{\mathrm{a}}$

\begin{tabular}{|c|c|c|c|c|c|c|}
\hline Classification accuracy & Class 1 & Class 2 & Class 3 & Class 4 & Class 5 & User $(\%)$ \\
\hline \multicolumn{7}{|l|}{ Five-level } \\
\hline Class 1 & 8 & 10 & 14 & 3 & 0 & 23 \\
\hline Class 2 & 9 & 19 & 13 & 3 & 1 & 42 \\
\hline Class 4 & 5 & 9 & 12 & 6 & 6 & 16 \\
\hline Class 5 & 4 & 3 & 7 & 2 & 1 & 6 \\
\hline Producer (\%) & 24 & 35 & 31 & 40 & 11 & $\ldots$ \\
\hline \multicolumn{7}{|l|}{ Three-level } \\
\hline Class 3 & 8 & & 98 & & 1 & 92 \\
\hline Class 4 & 5 & 9 & & 15 & & 52 \\
\hline Class 5 & 4 & 3 & 7 & & 15 & 52 \\
\hline Producer $(\%)$ & 73 & 91 & 82 & 71 & 88 & $\ldots$ \\
\hline
\end{tabular}

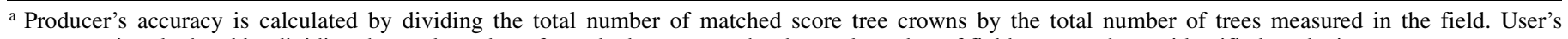
accuracy is calculated by dividing the total number of matched score trees by the total number of field-measured trees identified on the imagery. 
maximizing the discriminating potential of image interpretation algorithms $(18,56)$.

Once the classification system was applied, the use of a clustering approach to produce a coherent image of tree crowns rather than a simple pixel-by-pixel interpretation of the image was undertaken. This procedure is an example of very simplified individual tree delineation routines which have been applied with success to high spatial resolution images of forested environments $(23,24)$. In this example, we utilized imagery with a small view angle and obtained imagery under close to optimum sun angle conditions. The effect of sun and view angle on forested imagery can have a significant effect, due to shadowing and viewing distortions (35). Any ongoing monitoring program utilizing remote sensing technology needs to be aware of the potential effect of changing in these conditions. The continued improvement of these types of image analysis and interpretation techniques will allow both the selection of individual tree crowns for model development and the spatial extrapolation of the relationships between spectra and crown condition features, such as Dothistroma needle blight score, to be automated. This, in turn, allows these assessments to be integrated easily into forest management systems.

\section{ACKNOWLEDGMENTS}

Funding for this research was provided by State Forests of New South Wales; CSIRO Forestry and Forest Products, Canberra; and the Forest and Wood Products Research and Development Corporation (FWPRDC, PN99.814), Melbourne, Australia. We thank P. Ryan (CSIRO FFP) and C. Beadle (CSIRO FFP) for advice throughout the project, R. Gibbs (CSIRO FFP) for help with fieldwork, and A. Carroll (Pacific Forestry Centre, Canadian Forest Service) and M. Dick and G. Hosking (New Zealand Forest Research Institute) for useful comments and discussions on this article.

\section{LITERATURE CITED}

1. Ahern, F. J. 1988. The effects of bark beetle stress on the foliar spectral reflectance of lodgepole pine. Int. J. Remote Sens. 9:1451-1468.

2. Blackburn, G. A. 1999. Relationship between spectral reflectance and pigment concentrations in stacks of deciduous broadleaves. Remote Sens. Environ. 70:224-237.

3. Carter, G. A. 1994. Ratios of leaf reflectance in narrow wavebands as indicators of plant stress. Int. J. Remote Sens. 15:697-703.

4. Carter, G. A., Dell, T. R., and Cibula, W. G. 1996. Spectral reflectance characteristics and digital imagery of a pine needle blight in the southeastern United States. Can. J. For. Res. 26:402-407.

5. Carter G. A., and Knapp, A. K. 2001 Leaf optical properties in higher plants: Linking spectral characteristics to stress and chlorophyll concentration. Am. J. Bot. 88:677-684.

6. Carter, G. A., and Miller, R. L. 1994. Early detection of plant stress by digital imaging within narrow stress-sensitive wavebands. Remote Sens. Environ. 50:295-302.

7. Carter, G. C. 1993. Responses of leaf spectral reflectance to plant stress. Am. J. Bot. 80:239-243.

8. Coops, N. C., Stone, C., Culvenor, D. S., Chisholm, L., and Merton, R. 2002. Predicting chlorophyll content in eucalypt vegetation at the leaf and canopy level using high spectral resolution imagery. Tree Physiol. 23:23-31.

9. Curran, P. J. 1994. Attempts to drive ecosystem simulation models at local to regional scales. Pages 149-166 in: Environmental Remote Sensing from Regional to Global Scales. G. M. Foody and P. J. Curran, eds. Wiley, Chichester.

10. Curran, P. J., Dungan, J. L., and Gholz, H. L. 1990. Exploring the relationship between reflectance red-edge and chlorophyll content in slash pine. Tree Physiol. 7:33-48.

11. Curran, P. J., Dungan, J. L., Macler, B. A., and Plummer, S. E. 1991. The effect of a red leaf pigment on the relationship between red edge and chlorophyll concentration. Remote Sens. Environ. 35:69-76.

12. Curran, P. J., Windham, W. R., and Gholz, H. L. 1995. Exploring the relationship between reflectance red edge and chlorophyll concentration in slash pine leaves. Tree Physiol. 15:203-206.

13. Devlin, R. M., and Witham, F. H. 1983. Plant Physiology, 4th ed. Willard Grant Press, Boston.

14. Edwards, D. W., and Walker, J. 1978. Dothistroma needle blight in Australia. Aust. For. Res. 8:125-137.
15. Elvidge, C. D., and Chen, Z. K. 1995. Comparison of broad-band and narrow-band red and near-infrared vegetation indexes. Remote Sens. Environ. 54:38-48.

16. Everitt, J. H., Richardson, A. J., and Gausman, H. W. 1985. Leaf reflectance-Nitrogen-chlorophyll relations in buffelgrass. Photogramm. Eng. Remote Sens. 51:463-466.

17. Everitt, J. H., Richerson, J. V., Karges, J. P., and Davis, M. R. 1997. Using remote sensing to detect and monitor a western pine beetle infestation in west Texas. Southwest. Entomol. 22:285-292.

18. Fournier, R. A., Rich, P. M., and Landry, R. 1997. Hierarchical characterization of canopy architecture for boreal forest. J. Geophys. Res. 102(D24):29445-29454.

19. Franklin, S. E., and Raske, A. G. 1994. Satellite remote sensing of spruce budworm forest defoliation in western Newfoundland. Can. J. Remote Sens. 20:37-48.

20. Gamon, J. A., and Surfus, J. S. 1999. Assessing leaf pigment content and activity with a reflectometer. New Phytol. 143:105-117.

21. Gibson, I. A. S. 1979. Pages 73-76 in: Diseases of Forest Trees Widely Planted as Exotics in the Tropics and Southern Hemisphere, Part II. The Genus Pinus. Commonwealth Mycological Institute, Kew, Surrey, and Commonwealth Forestry Institute, University of Oxford, Oxford.

22. Goetz, A. F. N., Rock, B. N., and Rowan, L. C. 1983. Remote sensing for exploration: An overview. Econ. Geol. 78:5773-5790.

23. Gougeon, F. A. 1995. A crown-following approach to the automatic delineation of individual tree crowns in high spatial resolution aerial images. Can. J. Remote Sens. 21:274-284.

24. Gougeon, F. A., and Leckie, D. 1999. Forest regeneration: Individual tree crown detection techniques for density and stocking assessment. Pages 169-177 in: Proc. Int. Forum on Automated Interpretation of High Spatial Resolution Digital Imagery for Forestry. D. A. Hill and D. G. Leckie, eds. Natural Resources Canada, Can. For. Serv. Victoria, Canada.

25. Hall, R. J., Crown, P. H., Titus, S. T., and Volney, W. J. A. 1995. Evaluation of Landsat Thematic Mapper data for mapping top kill caused by jack pine budworm defoliation. Can. J. Remote Sens. 21:388-399.

26. Hansen, E. M., and Lewis, K. J. (eds.) 1997. Compendium of Conifer Diseases. The American Phytopathological Society, St. Paul, MN.

27. Hays, W. L. 1988. Statistics. 4th ed. CBS College Publishing, New York.

28. Hoque, E., Hutzler, P. J. S., and Hiendl, H. 1992. Reflectance, colour and histological features as parameters for the early assessment of forest damages. Can. J. Remote Sens. 18:104-110.

29. Isbell, R. F. 1996. The Australian Soil Classification. CSIRO Publishing, Collingwood, Victoria, Australia.

30. Ivory, M. H. 1994. Records of foliar pathogens of Pinus species in tropical countries. Plant Pathol. (Oxf.) 43:511-518.

31. Kruse, F. A., Kierein-Young, K. S., and Boardman, J. W. 1990. Mineral mapping at Cuprite, Nevada with a 63-channel imaging spectrometer. Photogramm. Eng. Remote Sens. 56:83-92.

32. Kumar, M., and Monteith, J. L. 1982. Remote sensing of plant growth. Pages 133-144 in: Plants and the Daylight Spectrum. H. Smith, ed. Academic Press, London.

33. Leckie, D. G., Ostaff, D. P., Teillet, P. M., and Fedosjevs, G. 1989. Spectral characteristics of tree components of balsam fir and spruce damaged by spruce budworm. For. Sci. 35:582-600.

34. Leckie, D. G., Yuan, X., Ostaff, D. P., Piene, H., and Maclean, D. A. 1992. Analysis of high resolution multispectral MEIS imagery for spruce budworm damage assessment on a single tree basis. Remote Sens. Environ. 40:125-136.

35. Li, X., and Strahler, A. H. 1985. Geometric-optical modelling of a conifer forest canopy. IEEE Trans. Geosci. Remote Sens. GE 23:705-721.

36. Lillesand, T. M., and Kiefer, R. W. 1994. Remote Sensing and Image Interpretation. John Wiley and Sons, New York.

37. Luther, J. E., Franklin S. E., Hudak, J., and Meades J. P. 1997. Forecasting the susceptibility and vulnerability of Balsam Fir stands to insect defoliation with Landsat Thematic Mapper data. Remote Sens. Environ. 59:77-91.

38. Malthus, T. J., and Madeira, A. C. 1993. High resolution spectroradiometry: Spectral reflectance of field bean leaves infected by Botrytis fabae. Remote Sens. Environ. 45:107-116.

39. Marks, G. C., Smith, I. W., and Cook, I. O. 1989. Spread of Dothistroma septospora in plantations of Pinus radiata in Victoria between 1979 and 1988. Aust. For. 52:10-19.

40. Merton, R. N. 1999. Multi-temporal analysis of community scale vegetation stress with imaging spectroscopy. Ph.D. thesis. University of Auckland, New Zealand.

41. Merton, R. N., and Harvey, L. E. 1997. Analysis of seasonal changes in Jasper Ridge vegetation biochemistry and biophysiology using multitemporal hyperspectral data. ASPRS Conf. Proc. Seattle, WA.

42. Nilsson, H. E. 1995 Remote sensing and image analysis in plant pathology. Annu. Rev. Phytopathol. 15:489-527. 
43. Peñuelas, J., and Filella, I. 1998. Visible and near-infrared reflectance techniques for diagnosing plant physiological status. Trends Plant Sci. 3:151-156.

44. Peterson, G. W. 1982. Dothistroma needle blight of pines. For. Insect Dis. Leaflet 143. U.S. Dep. Agric. For. Serv. Washington, DC.

45. Podger, F. D. 1990. The biology, distribution and origins of Dothistroma septospora the cause of red-band needle blight of pines. Aust. For. Grow. 13:(Special liftout section No. 14).

46. Research Systems Inc. 2001. ENVI Version 3.4 User's Guide. Research Systems Inc., Boulder, CO.

47. Rock, B. N., Hoshizaki, T., and Miller, J. R. 1988. Comparison of in situ and airborne spectral measurements of the blue shift associated with forest decline. Remote Sens. Environ. 24:109-127.

48. Rouse, J. W., Jr., Haas, R. H., Schell, J. A., and Deering, D. W. 1973. Monitoring vegetation systems in the Great Plains with ERTS. Pages 309-317 in: Third ERTS Symposium, NASA SP-351, Vol. 1, U.S. Gov. Print. Off. Washington, DC.

49. Sellers, P. J. 1985. Canopy reflectance, photosynthesis and transpiration. Int. J. Remote Sens. 68:1335-1372.

50. Sellers, P. J. 1987. Canopy reflectance, photosynthesis, and transpiration 2. The role of biophysics in the linearity of their interdependence. Remote Sens. Environ. 21:143-183.

51. Sinclair, W. A., Lyon, H. H., and Johnson, W. T. 1987. Diseases of Trees and Shrubs. Cornell University Press, Ithaca, NY.

52. Stone, C. 1996. The role of psyllids (Hemiptera:Psyllidae) and bell miners (Manorina melanophrys) in canopy dieback of Sydney blue gum (Eucalyptus saligna Sm.). Aust. Ecol. 21:450-458.
53. Stone, C., Chisholm, L., and Coops, N. C. 2001. Spectral reflectance characteristics of Eucalypt foliage damaged by insects. Aust. J. Bot. 49:687-698.

54. Thenkabail, P. S., Smith, R. B., and De Pauw, E. 2000. Hyperspectral vegetation indices and their relationships with agricultural crop characteristics. Remote Sens. Environ. 71:158-182.

55. Thomas, J. R., and Gausman, H. W. 1977. Leaf reflectance vs. leaf chlorophyll and carotenoid concentrations for eight crops. Agron. J. 69:799-811.

56. Treitz, P., and Howarth, P. 1996. Remote sensing for forest ecosystem characterization: A review. NODA/ NFP Tech. Rep. Tr-12. Nat. Resource Can. Can. For. Serv. Sault Ste. Marie, Ontario, Canada.

57. Vogelmann, J. E., and Rock, B. N. 1989. Use of Thematic Mapper data for the detection of forest damage caused by the pear thrips. Remote Sens. Environ. 30:217-225.

58. Vogelmann, J. E., Rock, B. N., and Moss, D. M. 1993. Red edge spectral measurements from sugar maple leaves. Int. J. Remote Sens. 14:15631575 .

59. Wessman, C. A. 1994. Estimating canopy biochemistry through imaging spectrometry. Pages 39-56 in: Imaging Spectrometry-A Tool for Environmental Observations. J. Hill and J. Megier, eds. Kluwer Academic, Dordrecht, The Netherlands.

60. Wilson, B. A., Luther, J. E., and Stuart, T. D. T. 1998. Spectral reflectance characteristics of Dutch Elm Disease. Can. J. Remote Sens. 24:200-205.

61. Winer, B. J. 1962. Statistical Principles in Experimental Design. McGraw-Hill, New York. 